\title{
The Role of Several Multidrug Resistance Systems in Erwinia chrysanthemi Pathogenesis
}

\author{
Alfredo Maggiorani Valecillos, Pablo Rodríguez Palenzuela, and Emilia López-Solanilla \\ Departamento de Biotecnología, Universidad Politécnica de Madrid, E.T.S. Ingenieros Agrónomos, Avda. Complutense S/N, \\ E-28040 Madrid, Spain
}

Submitted 30 September 2005. Accepted 1 February 2006.

\begin{abstract}
The role of several multidrug resistance (MDR) systems in the pathogenicity of Erwinia chrysanthemi 3937 was analyzed. Using the blast algorithm, we have identified several MDR systems in the $E$. chrysanthemi genome and selected two acridine resistance (Acr)-like systems, two Emr-like systems, and one member of the major facilitator superfamily family to characterize. We generated mutants in genes encoding for these systems and analyzed the virulence of the mutant strains in different hosts and their susceptibility to antibiotics, detergents, dyes, and plant compounds. We have observed that the mutant strains are differentially affected in their virulence in different hosts and that the susceptibility to toxic substances is also differential. Both Acr systems seem to be implicated in the resistance to the plant antimicrobial peptide thionin. Similarly, the emr1AB mutant is unable to grow in the presence of the potato protein tuber extract and shows a decreased virulence in this tissue. These results indicate that the function of these systems in plants could be related to the specificity to extrude a toxic compound that is present in a given host.
\end{abstract}

Additional keywords: efflux pumps, resistance to plant antimicrobial peptides, soft-rot disease.

Erwinia chrysanthemi is one of the causal agents of the bacterial soft-rot disease, an economically important plant disease (Agrios 1998). The virulence of this pathogen is due to several factors, including pectate lyases and other hydrolytic enzymes, that degrade the plant cell wall, causing the maceration and eventual necrosis of plant tissues (Alfano and Collmer 1997; Barras et al. 1994). Other factors that are known to contribute to the virulence include iron transport functions (Expert 1999; Franza et al. 1999) and hrp genes, which encode a type III secretion system (Alfano and Collmer 1997). However, a successful pathogen must be able to overcome several barriers present in the host. Recently, considerable attention has been paid to the role of bacterial resistance to the host environment, such as the ability to detoxify reactive oxygen species (El Hassouni et al. 1999; Miguel et al. 2000), resistance to plant antimicrobial peptides (Lopez-Solanilla et al. 1998, 2001), and the survival at acidic pH (Llama-Palacios et al. 2003, 2005).

Plants produce many secondary metabolites, such as phytoalexins and alkaloids, which are likely to play a role in protecting plants against pathogens (Dixon 2001). On other hand, microbial pathogens have evolved mechanisms to counteract the

Corresponding author: E. López-Solanilla; Fax: +34 91 3365695; E-mail: emilia.lopez@upm.es presence of toxic substances such as the multidrug resistance (MDR) efflux pumps.

Multidrug efflux transporters can recognize and extrude many different organic compounds (often structurally dissimilar), providing resistance to multiple antimicrobial compounds. Genes encoding MDRs are plentiful and ubiquitous among gram-negative bacteria, constituting on average more than $10 \%$ of the transporters in an organism. There have been five families of MDRs characterized in bacteria (Paulsen 2003): the major facilitator superfamily (MFS), the resistance/nodulation/ cell division (RND) family, the small multidrug resistance (SMR) family, the multidrug and toxic compound efflux (MATE) family, and the ATP-binding cassette (ABC) family. Most of them utilize the transmembrane electrochemical gradient of protons or sodium ions to expel drugs from the cell. In contrast, the ABC transporters use the free energy from ATP hydrolysis. The most important MDRs in gram-negative bacteria fall into the RND family. These transporters work in conjunction with a periplasmic membrane fusion protein and an outer membrane protein (Saier 2000) which may facilitate the transport of molecules directly from the periplasmic space.

A reasonable hypothesis is that MDRs confer resistance to plant toxic compounds and this contributes to the ability of the bacterium to colonize the host and, therefore, to cause disease. Palumbo and associates (1998) found that an isoflavonoid efflux pump of Agrobacterium tumefaciens is involved in the competitive colonization of alfalfa roots. Other recent reports are in line with this idea; for example, Barabote and associates (2003) reported that the inactivation of TolC in E. chrysanthemi 3937 has a dramatic effect in pathogenesis. TolC is the outer membrane component of several MDRs in the RND family; thus, this mutation probably affects the function of a large number of transporters at the same time. Also, Burse and associates (2004) found that the mutation in the acridine resistance (Acr)AB transporter of E. amylovora resulted in a reduction in virulence on apple trees. Tegos and associates (2002) described the potential antimicrobial activity of some plant compounds through the inhibition of MDRs. Their results support the hypothesis that MDR-mediated resistance to toxics is important for bacterial pathogenesis and suggest that the combination of plant antimicrobials and MDR inhibitors may enhance inhibition of bacterial growth.

The availability of the complete sequences of several bacterial genomes has allowed functional genomic approaches to studying MDRs by identification of structurally related candidate genes in the genomes, which can be followed by systematic mutation and phenotypic analysis. The complete genome of $E$. chrysanthemi 3937 recently has been sequenced (United States Department of Agriculture 2001-04679 Genome Sequencing and Analysis of E. chrysanthemi 3937 9/15/01-9/14/03. Co-P.I. 
Nicole T. Perna, Co-P.I. Noel T. Keen, Co-P.I. Frederick R. Blattner, University of Wisconsin-Madison, Department of Animal Health and Biomedical Sciences, Genome Center of Wisconsin, Madison, U.S.A.). The preliminary sequence and annotation data is available at the TIGR and ASAP websites. Using the sequence data, we have identified several MDR candidate genes in this pathogen and the functionality of these genes has been analyzed by directed mutagenesis and analysis of susceptibility to several toxic substances and virulence in different hosts.

\section{RESULTS}

\section{Identification and cloning \\ of candidate MDR genes in E. chrysanthemi.}

To identify candidates MDR systems in this bacterium, we performed BLAST analysis using well-known MDR genes from other bacteria as query sequences. We selected nine MDR gene candidates belonging to different families for further analysis. Most of the selected genes previously were annotated in ASAP as putative MDR systems. The sequence similarities of the selected genes to other known transporters, as well as their ASAP identification numbers, are shown in Table 1. In short, we selected two systems with similarity to the multidrug efflux pump Acr (RND family), another two systems similar to the Emr pump (MFS family), and one candidate (Mlr) belonging to the MFS family. The two Acr- and Emr-like systems were designated Acr1AB, Acr2AB, Emr1AB, and Emr2AB, respectively.
In both cases, the DNA sequence identities between systems one and two were approximately $46 \%$. Components A and B in the systems Acr1 and 2 and Emr1 and 2 are contiguous in the genome of E. chrysanthemi. Bioinformatic evidence suggests that both components in each system are organized as an operon.

\section{Generation and analysis of MDR-deficient mutants.}

To determine the role of the MDR systems in E. chrysanthemi 3937 pathogenicity, the selected genes were subjected to $\mathrm{Tn} 7$ in vitro mutagenesis, and the corresponding mutagenized construct, bearing a copy of the $\mathrm{Tn} 7$ transposon within the target gene, was marker-exchanged into the E. chrysanthemi 3937 chromosome.

In all cases, the marker-exchange mutations were verified by polymerase chain reaction (PCR) amplification of the target gene from the chromosome using specific primer pairs (data not shown). Also, these strains were complemented by transforming the mutant strains with a plasmid expressing the wildtype gene. Mutant strains generated in this work are summarized in Table 2.

The growth curves of all mutant strains in rich media were determined. All strains, except the emrlAB mutant, were indistinguishable from the wild type. In stationary phase, this mutant strain showed an optical density at $600 \mathrm{~nm} \mathrm{15 \%} \mathrm{lower}$ than that of the wild type (data not shown).

The impact of the selected mutations on the pathogenicity of E. chrysanthemi 3937 was evaluated in chicory leaves by meas-

Table 1. Sequence similarities (BLASTP) of the multidrug resistance transporters found in Erwinia chrysanthemi

\begin{tabular}{|c|c|c|c|c|}
\hline Transporter $^{\mathbf{a}}$ & Closest homology ${ }^{b}$ & $\begin{array}{c}\text { Identity } \\
(\%)\end{array}$ & $\begin{array}{c}\text { Similarity } \\
(\%)\end{array}$ & $\begin{array}{l}\text { ASAP feature } \\
\text { identification }\end{array}$ \\
\hline Mlr & Putative MFS transporter Yersinia pseudotuberculosis IP 32953 & 24 & 40 & ABF-0015499 \\
\hline \multicolumn{5}{|c|}{ 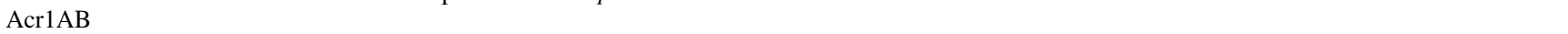 } \\
\hline Acr1A(MFP) & Acridine efflux pump $Y$. pestis KIM & 59 & 70 & ABF-0017391 \\
\hline Acr1B(IMP) & Putative efflux pump Escherichia coli O157:H7EDL933 & 59 & 71 & ABF-0017392 \\
\hline \multicolumn{5}{|c|}{ 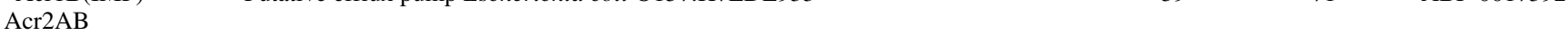 } \\
\hline Acr $2 \mathrm{~A}(\mathrm{MFP})$ & Acriflavine resistance protein Erwinia carotovora subsp. atroseptica SCRI1043 & 69 & 79 & ABF-0019532 \\
\hline Acr2B(IMP) & Acriflavine resistance protein E. carotovora subsp. atroseptica SCRI1043 & 72 & 81 & ABF-0019534 \\
\hline \multicolumn{5}{|l|}{ Emr1AB } \\
\hline Emr1A(MFP) & Multidrug resistance protein E. carotovora subsp. atroseptica SCRI1043 & 70 & 82 & ABF-0015971 \\
\hline Emr1B(IMP) & Multidrug resistance protein E. carotovora subsp. atroseptica SCRI1043 & 77 & 84 & ABF-0015970 \\
\hline \multicolumn{5}{|c|}{$x_{0}$} \\
\hline Emr2A & Multidrug resistance protein Pseudomonas aeruginosa & 51 & 67 & ABF-0015787 \\
\hline Emr2B & Permease of the MFS $P$. aeruginosa UCBPP-PA14 & 53 & 67 & ABF-0015786 \\
\hline
\end{tabular}

${ }^{\mathrm{a}} \mathrm{MFP}=$ membrane fusion protein and IMP $=$ inner membrane protein.

${ }^{\mathrm{b}}$ MFS $=$ major facilitator superfamily.

Table 2. Bacterial strains and plasmids used in this study

\begin{tabular}{|c|c|c|}
\hline Designation & Relevant characteristics & Source of reference \\
\hline Escherichia coli $\mathrm{DH} 5 \alpha$ & supE44 Alac U169 ( $\phi 80$ lacZM15)hsdR17 recA1 endA1 gyrA96 thi-1 relA1 & Hanahan 1983 \\
\hline \multicolumn{3}{|c|}{ 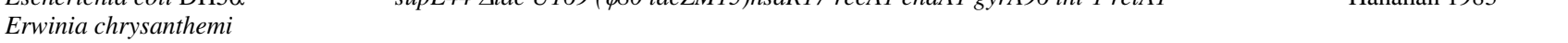 } \\
\hline 3937 & Wild-type strain & Chatterjee et al. 1983 \\
\hline$m l r$ & $m l r:: \operatorname{Tn} 7 \mathrm{Kan}^{\mathrm{r}}$ derivative of 3937 & This work \\
\hline acrlAB & acrlA:: $\operatorname{Tn} 7 \mathrm{Kan}^{\mathrm{r}}$ derivative of 3937 & This work \\
\hline$a c r 2 A B$ & acr2A:: $\operatorname{Tn} 7 \mathrm{Kan}^{\mathrm{r}}$ derivative of 3937 & This work \\
\hline acr $2 B$ & acr $2 B:: \operatorname{Tn} 7 \mathrm{Kan}^{\mathrm{r}}$ derivative of 3937 & This work \\
\hline emrlAB & emrlA:: $\operatorname{Tn} 7 \mathrm{Kan}^{\mathrm{r}}$ derivative of 3937 & This work \\
\hline emrlB & emrlB:: $\mathrm{Tn} 7 \mathrm{Kan}^{\mathrm{r}}$ derivative of 3937 & This work \\
\hline emr $2 A B$ & emr2A:: $\operatorname{Tn} 7 \mathrm{Kan}^{\mathrm{r}}$ derivative of 3937 & This work \\
\hline$m l r^{*}$ & $m l r$ complemented with pGEM carrying $m l r$ gen & This work \\
\hline $\operatorname{acrl} A B^{*}$ & acr $1 A B$ complemented with pGEM carrying $a c r l A$ and $a \operatorname{cr} 1 B$ genes & This work \\
\hline $\operatorname{acr} 2 A B^{*}$ & acr $2 A B$ complemented with pGEM carrying $a c r 2 A$ and $e m r 2 B$ genes & This work \\
\hline acr $2 B^{*}$ & acr $2 B$ complemented with pGEM carrying $a c r 2 B$ gen & This work \\
\hline emrlAB* & emrlAB complemented with pGEM carrying $e m r 1 A$ and $e m r l B$ genes & This work \\
\hline emrlB* & emrlB complemented with pGEM carrying emrlB gen & This work \\
\hline$e m r 2 A B^{*}$ & emr $2 A B$ complemented with pGEM carrying $e m r 2 A$ and $e m r 2 B$ genes & This work \\
\hline
\end{tabular}

${ }^{\mathrm{a}} \mathrm{Kan}^{\mathrm{r}}=$ kanamycin resistant. 
uring the macerated area $24 \mathrm{~h}$ postinoculation. The mutant strains $e m r l A B$ and $e m r l B$ did not differ significantly from the wild type (Fig. 1A). All of the other mutant strains showed a drastic reduction in their virulence.

Complementation experiments showed full restoration of virulence in chicory leaves for all except emr $2 A B$ and $a c r 2 A B$ mutant strains. In these two cases, we found only partial complementation, but there still was a marked improvement in pathogenesis over the mutant strains (Fig. 1A).

Virulence assays also were carried out in African violet (Saintpaulia ionantha), which is one of the typical hosts of $E$. chrysanthemi. The leaves were pair inoculated with the wildtype and a mutant strain and the area macerated by $24 \mathrm{~h}$ postinoculation was measured (Fig. 1B). In most cases, the behavior of the mutant strains was similar in the chicory and African violet assays. However, the $\operatorname{emr} l A B$ and $e m r l B$ mutants were reduced in virulence only on African violet and the $\operatorname{acr} 2 A B$ mutant was reduced in virulence only on chicory. Complementation data in African violet show restoration of virulence in all cases except the emr $2 A B$ mutant strain (Fig. 1B).

To further investigate the effect of these mutations on virulence, the ability of the bacteria to establish a population inside the plant was measured for a selected subset of strains. The mutants $\operatorname{acr} 1 A B, \operatorname{acr} 2 A B$, and $e m r 2 A B$, which are impaired in symptom production, also were impaired in growth in chicory leaves (Table 3 ). Cells of mutant emr $2 A B$ could not be recovered even directly after inoculation, which suggests that this mutant was affected drastically in its ability to initiate plant colonization. We cannot rule out the possibility that mutant emr $2 A B$ could be more sensitive to leaf compounds released during homogenization of plant tissue while isolating bacteria. In contrast, the bacterial population of the emrlAB strain, whose growth rate was reduced moderately in rich growth media, did not differ from that of the wild-type strain in planta. This is consistent with its behavior in the symptom production assay (Fig. 1A).

\section{Susceptibility of MDR-deficient mutants toward antibiotics and toxic compounds.}

The sensitivity of the mutants toward various antibiotics and other toxic compounds was determined and expressed as a percentage of the growth of the wild-type strain (Table 4). The toxic substances used in these assays included antibiotics, detergents, dyes, plant antimicrobial peptides, phythoalexins, and plant extracts.

The $\operatorname{acrlAB}$ strain showed increased sensitivity to the antibiotics carbenicillin, novobiocin and tetracycline, and to the plant antimicrobial peptide thionin. The $\operatorname{acr} 2 A B$ strain was affected in its sensitivity to the same toxic compounds as $\operatorname{acrl} A B$, as well as norfloxacin, chloramphenicol, naringenin, crystal violet, sodium dodecyl sulfate (SDS), linoleic acid, and the phytoalexin berberine.

The emrlAB strain showed increased sensitivity to the antibiotics carbenicillin, chloramphenicol, and tetracycline, and also to oleic acid. The most interesting feature of this mutant was the complete growth inhibition caused by the potato protein extract. In contrast, the mutation of the inner membrane protein of this system $($ emrlB) did not affect bacterial growth in the presence of potato extract. This result suggests that the Emr1AB system could play an essential role for bacterial virulence in potato tubers. To test this hypothesis, virulence assays were performed in potato tubers. The virulence of the mutant strain was reduced significantly compared with that of the wild-type strain, and the complemented mutant restored its virulence to the wild-type level (Fig. 2). None of the other mutant strains showed significant differences in virulence in this tissue (data not shown). The emr $2 A B$ strain was more sensitive to the antibiotics carbenicillin, norfloxacin, oxacillin, and novobiocin, as well as to the dye rhodamine $6 \mathrm{G}$, when compared with wild-type strain. Interestingly, it also was more sensitive to all the phytoalexins tested and to the antimicrobial peptide protamine. The $m l r$ strain did not show altered sensitivity to any compound except carbenicillin, to which all mutant strains were sensitive.

\section{DISCUSSION}

One of the most important steps in bacterial pathogenicity of plants is the establishment of an initial population in the host tissue. It is well known that the plant milieu is laden with both
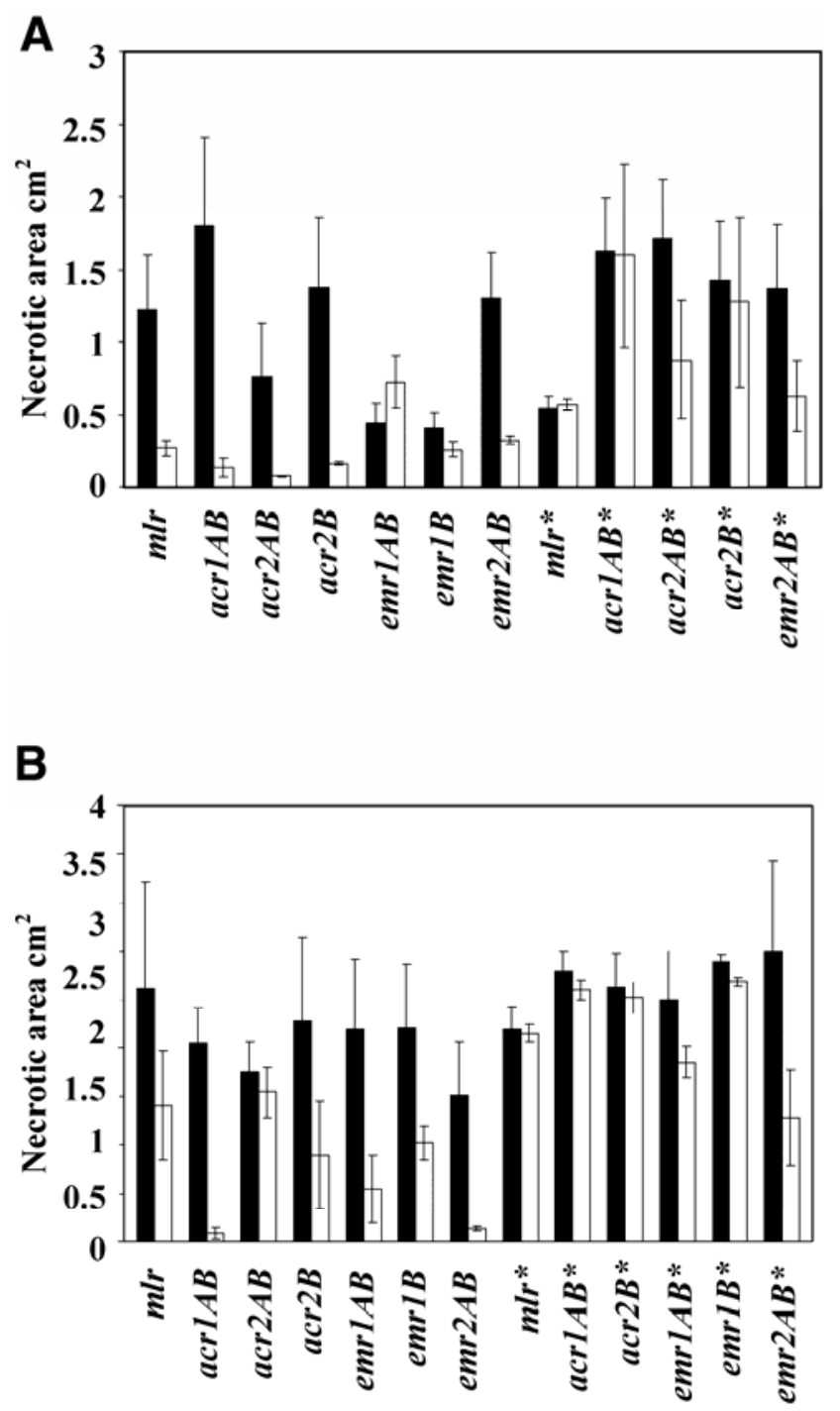

Fig. 1. Virulence of wild-type and mutant strains. A, Virulence on chicory leaves. Comparison of the virulence of Erwinia chrysanthemi 3937 wild-type (black bars) and mutant strains or complemented mutant strains (white bars) on chicory leaves. Two different experiments were performed and 10 leaves per experiment were inoculated, for each comparison, with the wild-type and with the correspondent mutant or complemented mutant strain in the same leaf. Necrotic area was determined after $24 \mathrm{~h}$ of incubation at $28^{\circ} \mathrm{C}$ with high humidity. Errors bars indicate standard errors. B, Virulence on Saintpaulia plants. Comparison of the virulence of E. chrysanthemi 3937 wild-type (black bars) and mutant strains or complemented mutant strains (white bars) on Saintpaulia plants. The Saintpaulia plants were inoculated in several leaves in a pairwise way to compare the wild-type strain with the mutant or complemented mutant strains. Fifteen leaves were analyzed in each comparison. Necrotic area was determined after $24 \mathrm{~h}$. of incubation at $28^{\circ} \mathrm{C}$ with high humidity. Errors bars indicate standard errors. 
preformed and induced antimicrobials (Dixon 2001); consequently, it has been shown that bacterial mechanisms involved in resistance to such substances play a pivotal role in virulence (Barabote et al. 2003; Burse et al. 2004; López-Solanilla et al, 1998, 2001; Titarenko et al. 1997).

MDR systems constitute one of the most important mechanisms for cell detoxification both in eukaryotes and prokaryotes (Paulsen 2003); therefore, these systems could be considered as potential virulence factors in plant pathogens. In this study, we have carried out a systematic approximation to the analysis of the relationship of MDR systems and virulence in the phytopathogenic bacteria $E$. chrysanthemi through the identification and mutagenesis of MDR systems in this pathogen, followed by experimental analysis of the implication in virulence. The main conclusion of this work is that a mutation in a given system has a dramatic effect on virulence. In contrast, the mutation in one of the genes encoding for a Pel enzyme has no apparent effects in virulence in most of the cases, and it is necessary to mutate several of these genes to observe a significant effect in virulence (Payne et al. 1987; Ried and Collmer 1988).

We have found two different systems with homology to the Acr family of transporters. Acr is a tripartite system and the most studied members of this family are AcrA/AcrB/TolC from Escherichia coli (Ma et al. 1993, 1995; Okusu et al. 1995; Paulsen et al. 1997) and MexA/MexB/OprM from Pseudomonas aeruginosa (Nikaido 1998). The system is composed of a periplasmic component, AcrA/MexA, belonging to the membrane fusion protein (MFP) family and an inner membrane component, AcrB/MexB, belonging to the resistance-nodulation divi- sion (RND) (Tseng et al. 1999). These complexes require an outer membrane protein for the substrate extrusion (TolC/OprM) (Paulsen et al. 1997). This MDR transporter confers resistance to lypophilic drugs, dyes, detergents, and bile acids.

The Acr-like systems (named 1 and 2) found in Erwinia chrysanthemi show clear sequence homology to several sequences from gram-negative bacteria (Table 1). They are paralogs with values of identity between 40 and $50 \%$. Our data also suggest that there is a functional divergence between both systems (see below). Interestingly, the Acr2AB system of $E$. chrysanthemi shows higher similarity with the unique AcrAB system characterized in another phytopathogenic bacterium, $E$. amylovora. (data not shown) (Burse et al. 2004).

The phenotype of the mutant strains in the AcrAB systems denotes that both have an essential role in virulence in chicory leaves, producing a necrotic area of 20 to $50 \%$ of that produced by the wild-type strain (Fig. 1A). Moreover, the bacterial population reached in planta by the mutant strains after $6 \mathrm{~h}$ was two orders of magnitude lower than that of the wild type. Interestingly, these two mutants behaved differently in Saintpaulia plants. In this host, the Acr1 AB system seems to have a larger contribution to virulence than in chicory leaves $(90 \%$ of reduction of necrotic area); however, the mutations in the Acr $2 \mathrm{AB}$ system had no effect on the virulence in this host. These results suggest that both systems are specialized for the detoxification of different substances from different hosts.

Overall, the mutation of the system Acr2AB increases the sensitivity of the bacterium to more toxic compounds tested than the mutations in Acr1AB system (Table 4). The profile of toxic substances to which the mutant $\operatorname{acr} 2 A B$ is susceptible is

Table 3. Bacterial population of wild-type and mutant strains in chicory leaves ${ }^{\mathrm{a}}$

\begin{tabular}{lccc}
\hline Strains in pairwise tests & Inoculum $\mathbf{C F U} / \mathbf{m l} \pm \mathbf{S E}$ & $\mathbf{C F U}$ in chicory leaf discs $(\boldsymbol{t}=\mathbf{0} \mathbf{h}) \pm \mathbf{S E}$ & $\mathbf{C F U}$ in chicory leaf discs $(\boldsymbol{t}=\mathbf{6} \mathbf{~ h}) \pm \mathbf{S E}$ \\
\hline 3937 & $9.4 \times 10^{5} \pm 5 \times 10^{3}$ & $2.3 \times 10^{5} \pm 3.5 \times 10^{3}$ & $2.2 \times 10^{6} \pm 1.2 \times 10^{4}$ \\
acrlAB & $8.9 \times 10^{5} \pm 5.1 \times 10^{3}$ & $1.9 \times 10^{5} \pm 3.3 \times 10^{3}$ & $1.7 \times 10^{4} \pm 1.1 \times 10^{2}$ \\
3937 & $9.4 \times 10^{5} \pm 5 \times 10^{3}$ & $1.9 \times 10^{5} \pm 3.7 \times 10^{3}$ & $2.6 \times 10^{6} \pm 2.7 \times 10^{4}$ \\
$a c r 2 A B$ & $1 \times 10^{6} \pm 7.7 \times 10^{3}$ & $1.5 \times 10^{5} \pm 7.6 \times 10^{3}$ & $1.4 \times 10^{4} \pm 2 \times 10^{2}$ \\
3937 & $9.4 \times 10^{5} \pm 5 \times 10^{3}$ & $2.2 \times 10^{5} \pm 5 \times 10^{3}$ & $2.1 \times 10^{6} \pm 3.4 \times 10^{4}$ \\
emrlAB & $9.1 \times 10^{5} \pm 7.2 \times 10^{3}$ & $2.5 \times 10^{5} \pm 3 \times 10^{3}$ & $2.5 \times 10^{6} \pm 3.1 \times 10^{4}$ \\
3937 & $9.4 \times 10^{5} \pm 5 \times 10^{3}$ & $2.1 \times 10^{5} \pm 3.8 \times 10^{3}$ & $2.4 \times 10^{6} \pm 2.9 \times 10^{2}$ \\
emr $2 A B$ & $1.1 \times 10^{5} \pm 9.5 \times 10^{3}$ & 0 & 0 \\
\hline
\end{tabular}

${ }^{\mathrm{a}} \mathrm{SE}=$ standard error, $t=$ time.

Table 4. Relative growth (\%) of the wild-type (WT) and mutant strains in the presence of toxic compounds ${ }^{\mathrm{a}}$

\begin{tabular}{|c|c|c|c|c|c|c|c|c|}
\hline Toxin, concentration $(\mu \mathrm{g} / \mathrm{ml})$ & WT & $m l r$ & $\operatorname{acr} 1 A B$ & $\operatorname{acr} 2 A B$ & $\operatorname{acr} 2 B$ & emrlAB & emr1B & $e m r 2 A B$ \\
\hline Acriflavine, 300 & 100 & 59 & 56 & 56 & 92 & 70 & 69 & 47 \\
\hline Carbenicillin, 1 & 100 & 6 & 7 & 8 & 6 & 7 & 4 & 8 \\
\hline Chloramphenicol, 0.1 & 100 & 91 & 84 & 52 & 57 & 47 & 97 & 93 \\
\hline Erythromycin, 0.01 & 100 & 92 & 70 & 70 & 72 & 99 & 95 & 52 \\
\hline Novobiocin, 50 & 100 & 78 & 47 & $\mathbf{0}$ & $\mathbf{0}$ & 86 & 85 & 9 \\
\hline Oxacillin, 5 & 100 & 67 & 90 & 60 & 41 & 59 & 61 & 42 \\
\hline Tetracycline, 0.1 & 100 & 90 & 20 & 17 & 17 & 0 & 83 & 160 \\
\hline Norfloxacine, 0.001 & 100 & 63 & 61 & 50 & 61 & 59 & 60 & 47 \\
\hline Cristal violet, 50 & 100 & 108 & 121 & 40 & 39 & 127 & 150 & 95 \\
\hline Rhodamine6G, 100 & 100 & 78 & 61 & 89 & 62 & 101 & 105 & 32 \\
\hline Sodium dodecyl sulfate, 200 & 100 & 94 & 87 & 13 & 42 & 104 & 106 & 82 \\
\hline Triton X 100, 400 & 100 & 92 & 104 & 61 & 62 & 97 & 93 & 95 \\
\hline Linoleic acid, 300 & 100 & 60 & 82 & 50 & 62 & 58 & 58 & 40 \\
\hline Oleic acid, 400 & 100 & 59 & 73 & 59 & 92 & 40 & 77 & 76 \\
\hline Berberine, 500 & 100 & 96 & 118 & 43 & 107 & 109 & 89 & 16 \\
\hline Naringenin, 500 & 100 & 69 & 92 & 53 & 69 & 60 & 59 & 39 \\
\hline Quercetin, 30 & 100 & 83 & 78 & 60 & 83 & 81 & 79 & 42 \\
\hline Potato protein extract, 50 & 100 & 100 & 237 & 97 & 103 & $\mathbf{0}$ & 100 & 104 \\
\hline Chicory protein extract, 50 & 100 & 62 & 164 & 95 & 71 & 74 & 63 & 71 \\
\hline Thionin, 500 & 100 & 103 & 32 & 12 & 13 & 96 & 110 & 58 \\
\hline Protamine, 20 & 100 & 92 & 72 & 66 & 86 & 97 & 101 & 47 \\
\hline
\end{tabular}

${ }^{a}$ Values under $50 \%$ are in bold. 
similar to what is reported for the acrAB mutant of E. amylovora, which is consistent with the fact that this system shows a higher sequence similarity with the E. amylovora sequence. It should be noted that, although the Acr1AB system confers resistance to fewer of the toxic substances tested, when compared with the Acr $2 \mathrm{AB}$ system, the Acr1AB system still strongly affects virulence in both chicory and Saintpaulia plants. It is particularly interesting that both systems are implicated in the resistance to the plant antimicrobial peptide thionin. There is strong evidence about the role of antimicrobial peptides in the defence response of plants against pathogens (García-Olmedo et al. 1998, 2001).

In E. chrysanthemi, mutations in the outer membrane protein TolC have revealed that it is an important component in bacterial virulence (Barabote et al. 2003). It is known that TolC acts as an outer membrane protein associated with several MDRs, and it is expected that the absence of this protein had a strong effect because the bacterium remains devoid of a presumed high number of active MDR systems. Surprisingly, we have found similar effects in virulence by mutating individual systems.

We also have identified two systems in E. chrysanthemi with homology to emr genes (multidrug resistance in Escherichia coli) from other bacteria that belong to the MFS family (Colmer et al. 1998; Hee Lee and Shafer 1999; Lomovskaya and Lewis 1992). These types of systems consist of two components: EmrB, which has 12 to 14 transmembrane domains, and EmrA, which belongs to the MFP family. Similar to the AcrAB systems, the EmrAB systems work as a tripartite structure in association with an outer membrane component.

The Emr system in E. coli confers resistance to unrelated groups of toxic compounds (Lomovskaya and Lewis 1992). One of the most studied systems is the farAB transporter of Neisseria ghonorreae that is involved in resistance to hydrophobic antibacterial agents as free fatty acids and antibacterial peptides (Hee Lee and Shafer 1999).

The Erwinia chrysanthemi mutant strains in Emr1AB system did not show a significant reduction in virulence in chicory leaves (Fig. 1A), but did in Saintpaulia plants (Fig. 1B) and potato tuber (Fig. 2). This last host is particularly interesting because it is very susceptible to Erwinia spp. colonization and only mutant strains with severe defects in virulence show differences when compared with the wild-type strain. Again, we observed that the reduction in virulence of a mutant strain in a given host is not necessarily correlated with the virulence of that strain in other hosts.

The analysis of the sensitivity of emrAB mutants to different toxins reveals their implication in resistance to free organic acids (Table 4). This is in line with the phenotype reported for the farAB mutants of Neisseria spp. Moreover, the mutants altered in the Emr2AB system are more sensible to some antibiotics, phytoalexins, and antimicrobial peptides, and particularly to protamines. The farAB mutants of Neisseria spp. also are more susceptible to cysteine-rich antimicrobial peptides.

The mutant in the Emr1AB system was extraordinarily sensitive to the potato tuber extract. This result most likely explains why the ability of this strain to infect potato tubers is severely reduced. This data implies that there is an unidentified toxic component in potato tuber that is specifically extruded by this system.

Finally, mutation in the $m l r$ gene did not drastically alter virulence in Saintpaulia plants or potato tuber, whereas virulence in chicory was diminished. The growth of this mutant in the presence of the toxic compounds tested is not drastically affected, except in carbenicillin. It is noteworthy that it shows a reduction of $38 \%$ in its relative growth in the presence of chicory protein extract. Nevertheless, the existence of other types of toxic compounds in chicory, which would be the responsible of the impaired virulence observed for the mutant in this host, cannot be ruled out.

In this work, we have studied two types of mutations, those that affect both components of the system and those that affect component B only. In most of the cases, both strains have the same behavior regarding virulence and sensitivity to toxic compounds. In the cases we observed of different sensitivities between both strains, the strain harboring the mutation that affects both components showed increased sensitivity to toxic compounds. Particularly striking is the case of the Emr1AB system. The mutation that affects both components renders strain sensitivity to chloranmphenicol, tetracycline, and potato protein extract, which is not observed in the strain affected

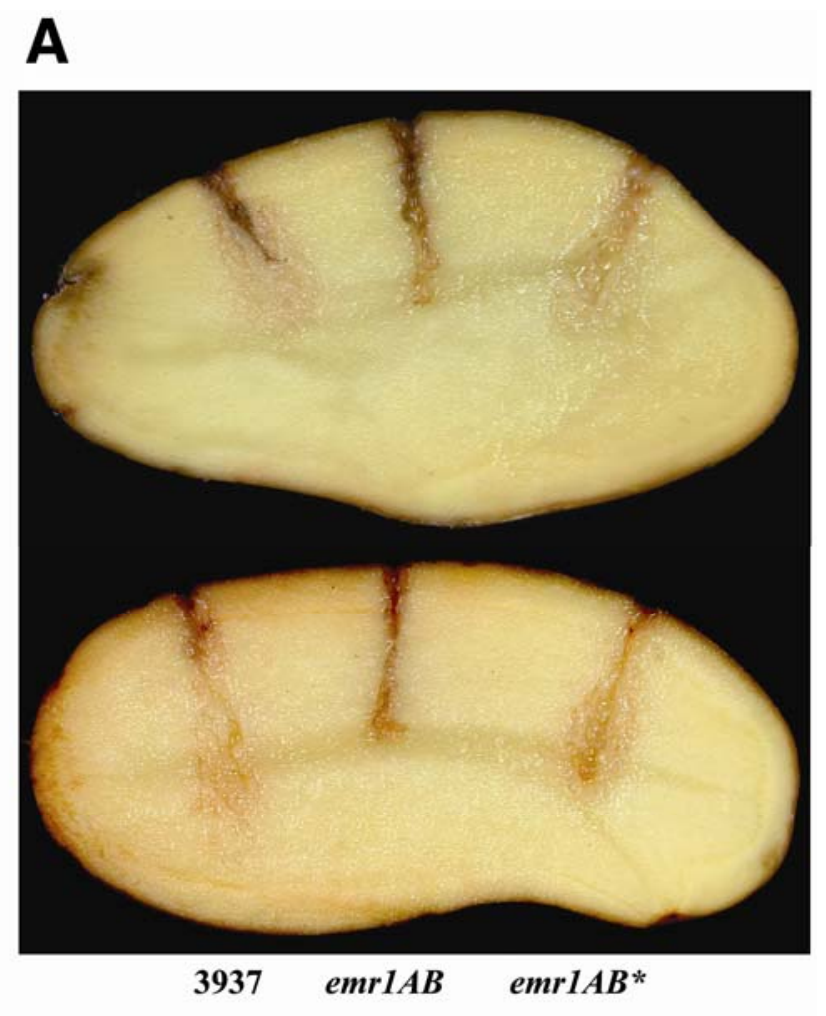

B

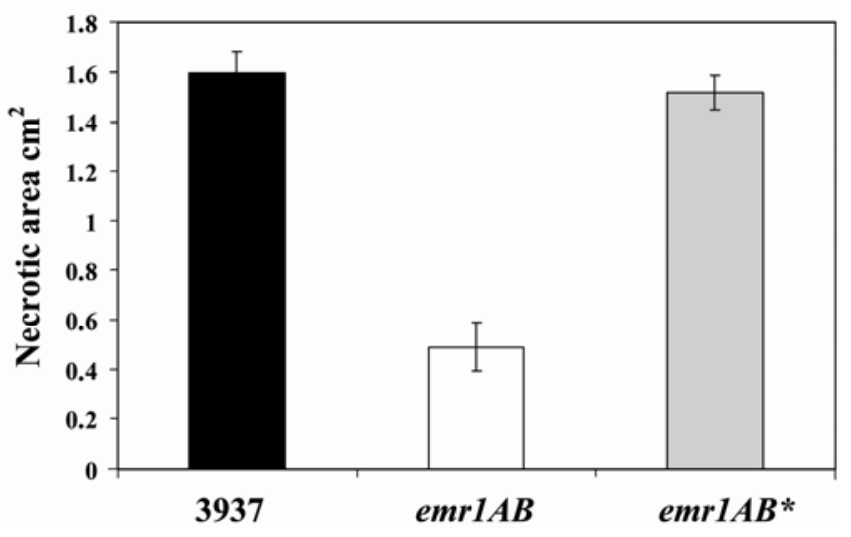

Fig. 2. Virulence of wild-type, emrlAB mutant strain, and $e m r l A B *$ complemented strain on potato tubers. A, Response of potato tubers to Erwinia chrysanthemi 3937, emr1AB, and emrlAB* strains. B, Comparison of the virulence of $E$. chrysanthemi 3937 wild-type (black bar), emrlAB mutant strain (white bar), and emr1 $\mathrm{AB} *$ complemented strain (gray bar) on potato tubers. The potato tubers were inoculated with the three strains and 20 tubers were analyzed. Necrotic area was determined after $24 \mathrm{~h}$ of incubation at $28^{\circ} \mathrm{C}$ with high humidity. Errors bars indicate standard errors. 
only in component B. One possible explanation relies on the existence of several paralogous systems in E. chrysanthemi and the possibility of the occurrence of functional complementation phenomena between components of different systems, which will merit future investigations.

In summary, these results highlight the relevance of resistance to toxic compounds for the virulence of E. chrysanthemi and strongly suggest that individual systems have very different roles in different hosts. Although these systems are responsible for the resistance in culture conditions to toxic compounds of very different nature, their function in planta could be related to the transport of a specific toxic compound that is present within a given host.

At the same time, these results uncover the multiplicity of preformed or inducible toxic substances present in plants, which probably play an essential role in the general phenomenon of resistance to bacterial pathogens.

These data point to the hypothesis, which will be the subject of further studies, that there is a correlation between host specificity and the presence, number, and activity of MDR systems found in bacterial pathogens.

\section{MATERIALS AND METHODS}

\section{Bacterial strains and culture conditions.}

Bacterial strains used in this work are described in Table 2. Strains of Escherichia coli were cultivated at $37^{\circ} \mathrm{C}$ in LuriaBertani medium. Strains of Erwinia chrysanthemi were cultivated at $30^{\circ} \mathrm{C}$ in nutrient broth (NB) (Difco Laboratories, Detroit) or King's B media (King et al. 1954) (Table 3). Antibiotics were added to the media at the following concentrations: ampicillin, $100 \mu \mathrm{g} / \mathrm{ml}$ and kanamycin, $20 \mu \mathrm{g} / \mathrm{ml}$.

\section{General DNA manipulation.}

Standard molecular biology techniques employed in this study were performed as described by Sambrook and associates (1989). DNA sequencing of both strands was done by the chain termination method on double-stranded DNA templates with an ABI Prism dye terminator cycle sequencing kit (Perkin-Elmer, Norwalk, CT, U.S.A.) in a 3100 DNA sequencer (Perkin-Elmer). Sequence alignments were performed at the National Center for Biotechnology Information with the BLAST network service, the Institute for Genomic Research BLAST, and with the Blast facility in the ASAP website.

\section{Cloning and mutagenesis of candidate MDR genes.}

The E. chrysanthemi MDR genes were amplified by PCR using the correspondent forward and reverse pair of oligonucleotides (Table 5) and cloned in pGEMT-easy (Promega Corp., Madison, WI, U.S.A.).

Tn7 in vitro mutagenesis was performed with the genomic

Table 5. DNA primers used in this study

\begin{tabular}{ll}
\hline Primers & \multicolumn{1}{c}{ Sequences $\left(\mathbf{5}^{\prime}\right.$ to $\mathbf{3}^{\prime}$ ) } \\
\hline Acr1AF & TGGTTGTCGTCGTCGTCATCAT \\
Acr1AR & ACTTGGTCACCGTGATGCCTT \\
Acr2AF & ACATGCAGTGGATCATCAGG \\
Acr2AR & GGCATTGCCAGTTGCAGTTT \\
Acr2B F & AATCCGGATCACAATCTGCTGC \\
Acr2B R & TTCGCCTTCGTGCTCATAGGTT \\
Emr1A F & AGGCTTTGGGACAGTGGAATGA \\
Emr1A R & TTGGATCGAACGGCGTGAAA \\
Emr2A F & AACAGCAGCACCGAAACGAT \\
Emr2A R & TCTACCCGCTTGGCTTGCTTAT \\
Mlr F & TATTGGCGATCGACTCCGGTTT \\
Mlr R & TTTCAACTGTGGCGGCAACT \\
\hline
\end{tabular}

priming system kit (GPS-1; New England Biolabs, Beverly, MA, U.S.A.). One mutagenized construction of each gene bearing the $\mathrm{Tn} 7$ transposon was selected and crossed into the chromosome by marker exchange as previously described (Hugouvieux-Cotte-Pattat and Robert-Baudouy 1992). The mutant was verified by PCR (data not shown) of the specific loci using the bacterial chromosome as a template. The corresponding mutant strains were selected for further analysis.

\section{Susceptibility assays.}

The susceptibility assays were carried out in liquid medium using microtiter plates. The inhibition experiments were repeated three times and the variation coefficients were smaller than $10 \%$ in all cases. The different toxic compounds tested were dissolved in the appropriate solvent at different concentrations and added to the microtiter wells in a constant volume of $57 \mu \mathrm{l}$ plus $33 \mu \mathrm{l}$ of NB (Difco Laboratories). Bacteria were inoculated at a final concentration of $10^{5} \mathrm{CFU} / \mathrm{ml}$ in a volume of $10 \mu \mathrm{l}$. After $24 \mathrm{~h}$ of incubation at $28^{\circ} \mathrm{C}$ in a Microbiology Workstation Bioscreen $\mathrm{C}$, growth was recorded by measuring absorbance at $600 \mathrm{~nm}$. Acriflavine, carbenicillin, chloramphenicol, erythromycin, novobiocin, oxacillin, tetracycline, norfloxacine, rhodamine6G, linoleic acid, oleic acid, berberine, naringenin, quercetin, and protamine were purchased from SigmaAldrich (St. Louis). Crystal violet was purchased from Panreac (Barcelona, España), Triton 100 from Merck (Darmstadl, Germany), and SDS 200 from USB corporation (Cleveland, $\mathrm{OH}$, U.S.A.). Thionin was purified from wheat flour, as described by Ponz and associates (1982). The chicory and potato extracts were obtained as follows: $200 \mathrm{~g}$ of frozen material was ground to powder in liquid nitrogen, using a mortar and pestle, and extracted once with $80 \mathrm{ml}$ of buffer $(0.1 \mathrm{M}$ Tris- $\mathrm{HCl}, 10 \mathrm{mM}$ EDTA, pH 7.5) and twice with $80 \mathrm{ml}$ of $\mathrm{H}_{2} \mathrm{O}$. The resulting pellet then was extracted with $50 \mathrm{ml}$ of $1.5 \mathrm{M} \mathrm{LiCl}$ at $4^{\circ} \mathrm{C}$ for 1 $\mathrm{h}$, and the extract was dialyzed against 5 liters of water using a Spectra/Por 6 (molecular weight cut-off, 3000; Spectrum, Laguna Hills, CA, U.S.A.) membrane and freeze dried. The extracts were resuspended in water.

\section{Virulence assays.}

Potato tubers (cv. Dessire) and heads of witloof chicory were purchased from a local supermarket. The cells from an overnight NB liquid medium culture were washed with $10 \mathrm{mM}$ $\mathrm{MgCl}_{2}$ by centrifugation and resuspended in an appropriate volume of the same buffer to obtain the desired inoculum concentration. Potato tubers were inoculated with $50 \mu \mathrm{l}$ of a suspension containing $5 \times 10^{4}$ bacteria, as described elsewhere (Lopez-Solanilla et al. 2001). Each potato tuber was inoculated pairwise with the wild-type strain and one of the mutant strains. Twenty potato tubers were analyzed in each case. The tubers were incubated in a moist chamber at $28^{\circ} \mathrm{C}$ for $24 \mathrm{~h}$. In the case of the strain $\operatorname{emrlAB}$, a second experiment was carried out inoculating the wild-type strain, the mutant, and the complemented mutant strain in the same tuber, and 20 potato tubers were analyzed.

Virulence assays on witloof chicory leaves were performed, as described by Bauer and associates (1994). The inoculum was $10 \mu \mathrm{l}$ of a bacterial suspension containing $10^{4}$ bacteria. Two different experiments were performed and 10 leaves per experiment were inoculated with each pair of compared strains. The leaves were incubated in a moist chamber at $28^{\circ} \mathrm{C}$ for $24 \mathrm{~h}$. To monitor bacterial growth in chicory leaves, the tissue was collected at different times and ground. The bacterial populations were estimated by dilution plating. The bacterial growth was monitorized three times in independent pairwise inoculations.

The Saintpaulia plants were inoculated in several leaves in a pairwise way to compare the wild-type strain with the mutant 
strains. The plants were incubated in a moist chamber at $28^{\circ} \mathrm{C}$ for $24 \mathrm{~h}$. Fifteen leaves were analyzed in each comparison between wild-type and mutant strain.

\section{ACKNOWLEDGMENTS}

This work was financed by the Ministerio de Educación y Ciencia, project AGL 2002-01412. A. M. Valecillos was a recipient of a fellowship from Instituto Nacional de Investigaciones Agrarias Venezuela. We gratefully thank A. Segura and P. Bronstein for critical reading of the manuscript and acknowledge $\mathrm{C}$. Rojas for technical assistance.

\section{LITERATURE CITED}

Agrios, G. 1998. Plant Pathology. Academic Press, New York.

Alfano, J. R., and Collmer, A. 1997. The type III (Hrp) secretion pathway of plant pathogenic bacteria: Trafficking harpins, Avr proteins, and death. J. Bacteriol. 179:5655-5662.

Barabote, R. D., Johnson, O. L., Eric, Z., San Francisco, S. K., Fralick, J. A., and San Francisco, M. J. D. 2003. Erwinia chrysanthemi tolC is involved in resistance to antimicrobial plant chemicals and is essential for phytopathogenesis. J. Bacteriol. 185:5772-5778.

Barras, F., van Gijsegem, F., and Chatterjee, A. K. 1994. Extracellular enzymes and pathogenesis of soft-rot Erwinia. Annu. Rev. Phytopathol. 32:201-234

Bauer, D. W., Bogdanove, A. J., Beer, S. V., and Collmer, A. 1994. Erwinia chrysanthemi hrp genes and their involvement in soft rot pathogenesis and elicitation of the hypersensitive response. Mol. Plant-Microbe Interact. 7:573-81.

Burse A., Weingart, H., and Ullrich, M. S. 2004.The phytoalexin-inducible multidrug efflux pump AcrAB contributes to virulence in the fire blight pathogen Erwinia amylovora. Mol. Plant-Microbe Interact. 17:43-54.

Chatterjee, A. K., Thurn, K. K., and Feese, D. A. 1983. Tn5 induced mutations in the enterobacterial phytopathogen Erwinia chrysanthemi. Appl. Environ. Microbiol. 45:644-650.

Colmer, J. A., Fracklic, J. A., and Hamood, A. N. 1998. Isolation and characterization of a putative multidrug resistance pump from Vibrio cholerae. Mol. Microbiol. 27:63-72.

Dixon, R. A. 2001. Natural products and plant disease resistance. Nature 14:843-847

El Hassouni, M., Chambost, J. P., Expert, D., Van Gijsegem, F. and Barras, F. 1999. The minimal gene set member $m s r A$, encoding peptide methionine sulfoxide reductase, is a virulence determinant of the plant pathogen Erwinia chrysanthemi. Proc. Natl. Acad. Sci. U.S.A. 96:887-892.

Expert, D. 1999. Withholding and exchanging iron: Interactions between Erwinia spp. and their plant hosts. Annu. Rev. Phytopathol. 37:307-333.

Franza, T., Sauvage, C., and Expert, D. 1999. Iron regulation and pathogenicity in Erwinia chrysanthemi 3937: Role of the fur repressor protein. Mol. Plant-Microbe Interact. 12:119-128.

García-Olmedo, F., Molina, A., Alamillo, J. M., and RodríguezPalenzuela, P. 1998. Plant defense peptides. Biopolymers 47:479-491.

García-Olmedo, F., Rodríguez-Palenzuela, P., Molina, A., Alamillo, J. M., López-Solanilla, E., Berrocal-Lobo, M., and Poza-Carrión, C. 2001. Antibiotic activities of peptides, hydrogen peroxide and peroxynitrite in plant defence. FEBS (Fed. Eur. Biol. Soc.) Lett. 498:219-222.

Hanahan, D. 1983. Studies on transformation of Escherichia coli with plasmids. J. Mol. Biol. 166:557-580.

Hee Lee, E., and Shafer, W. M. 1999. The farAB-encoded efflux pump mediates resistance of gonococci to long-chained antibacterial fatty acids. Mol. Microbiol. 33:839-845.

Hugouvieux-Cotte-Pattat, N., and Robert-Baudouy J. 1992. Analysis of the regulation of the pelBC genes in Erwinia chrysanthemi 3937. Mol. Microbiol. 6:2363-2376.

King, E. O., Ward, M. K., and Raney, O. E. 1954. Two simple media for the demonstration of pyocyanin and flurescein. J. Lab. Clin. Med. 44:301307.

Llama-Palacios, A., Lopez-Solanilla, E., Poza-Carrión, C., García-Olmedo, F., and Rodríguez-Palenzuela, P. 2003. The Erwinia chrysanthemi phoPphoQ operon plays an important role in growth at low $\mathrm{pH}$, virulence and bacterial survival in plant tissue. Mol. Microbiol. 49:347-356.

Llama-Palacios, A., Lopez-Solanilla, E., and Rodríguez-Palenzuela, P. 2005. Role of the PhoP-PhoQ system in the virulence of Erwinia chrysanthemi strain 3937: Involvement in sensitivity to plant antimicrobial peptides, survival at acid $\mathrm{pH}$, and regulation of pectolytic enzymes. J. Bacteriol. 187:2157-2162.

Lomovskaya O., and Lewis K. 1992. emr, an Escherichia coli locus for multidrug resistance. Proc. Natl. Acad. Sci. U.S.A. 89:8938-8942.

Lopez-Solanilla, E., García-Olmedo F., and Rodríguez-Palenzuela, P. 1998. Inactivation of the sapA to sapF locus of Erwinia chrysanthemi reveals common features in plant and animal bacterial pathogenesis. Plant Cell 10:917-924.

Lopez-Solanilla, E., Llama-Palacios, A., Collmer, A., Garcia-Olmedo, F., and Rodriguez-Palenzuela, P. 2001. Relative effects on virulence of mutations in the sap, pel, and hrp loci of Erwinia chrysanthemi. Mol Plant-Microbe Interact. 14:386-393.

Ma, D., Cook, D. N., Alberti, M., Pon, N. G., Nikaido, H., and Hearst, J. E. 1993. Molecular cloning and characterization of acrA and acrE genes of Escherichia coli. J. Bacteriol. 175:6299-6313.

Ma, D., Cook, D. N., Alberti, M., Pon, N. G., Nikaido, H., and Hearst, J. E. 1995. Genes $a c r A$ and $a c r B$ encode a stress-induced efflux system of Escherichia coli. Mol. Microbiol. 16:45-55.

Miguel, E., Poza-Carrion, C., Lopez-Solanilla, E., Aguilar, I., LlamaPalacios, A., Garcia-Olmedo, F., and Rodriguez-Palenzuela, P. 2000 Evidence against a direct antimicrobial role of $\mathrm{H}_{2} \mathrm{O}_{2}$ in the infection of plants by Erwinia chrysanthemi. Mol. Plant-Microbe Interact. 13:421429.

Nikaido, H. 1998. Antibiotic resistance caused by gram-negative multidrug efflux pumps. Clin. Infect. Dis. 27:S32-S41.

Okusu, H., Ma, D., and Nikaido, H. 1995. AcrAB efflux pump plays a major role in the antibiotic resistance phenotype of Escherichia coli multiple-antibiotic-resistance (Mar) mutants. J. Bacteriol. 178:306-308.

Palumbo, J. D., Kado, C. I. and Philips, D. A. 1998. An isoflavonoid-inducible efflux pump in Agrobacterium tumefaciens is involved in competitive colonization of roots. J. Bacteriol. 180:3107-3113.

Paulsen, I. T. 2003. Multidrug efflux pumps and resistance: Regulation and evolution. Curr. Opin. Microbiol. 6:446-451.

Paulsen, I. T., Park, J. H., Choi, P. S., and Saier, M. H., Jr. 1997. A family of Gram-negative bacterial outer membrane factors that function in the export of proteins, carbohydrates, drugs, and heavy metals from gramnegative bacteria. FEMS (Fed. Eur. Microbiol. Soc.) Microbiol. Lett. 156:1-8.

Payne, J. H., Shoedel, C., Keen, N. T., and Collmer, A. 1987. Multiplication and virulence in plant tissues of Escherichia coli clones producing pectate lyase isozymes PLb and PLe at high levels and of an Erwinia chrysanthemi mutant deficient in PLe. Appl. Environ. Microbiol. 53:2315-2320.

Ponz, F., Hernández-Lucas, C., Carbonero, P., and García-Olmedo, F. 1982. Lipid-binding proteins from the endosperms of wheat and oats. Phytochemistry 23:2178-2181.

Ried, J. L., and Collmer, A. 1988. Construction and characterization of an Erwinia chrysanthemi mutant with directed deletions in all of the pectate lyase structural genes. Mol. Plant-Microbe Interact. 1:32-38.

Saier, M. H., Jr. 2000. A functional-phylogenetic classification system for transmembrane solute transporters. Microbiol. Mol. Biol. Rev. 64:354411.

Sambrook, J., Fritsch, E. F., and Maniatis, T. 1989. Molecular Cloning: A laboratory Manual, 2nd ed. Cold Spring Harbor Laboratory Press, Cold Spring Harbor, NY, U.S.A.

Tegos, G., Stermitz, F. R., Lomovskaya, O., and Lewis, K. 2002. Multidrug pump inhibitors uncover remarkable activity of plant antimicrobials. Antimicrob. Agents Chemother. 46:3133-3141.

Titarenko, E., López-Solanilla, E., García-Olmedo, F., and RodríguezPalenzuela, P. 1997. Mutants of Ralstonia (Pseudomonas) solanacearum sensitive to antimicrobial peptides are altered in their lipopolysaccharide structure and are avirulent in tobacco. J. Bacteriol. 179:6699-6704.

Tseng, T., Gratwick, K. S., Kollman, J., Park, D., Nies, D. H., Goffau, A., and Saier, M. H., Jr. 1999. The RND permease superfamily: An ancient, ubiquitous and diverse family that includes human disease and developmental proteins. J. Mol. Microbiol. Biotechnol. 1:107-125.

\section{AUTHOR-RECOMMENDED INTERNET RESOURCES}

The Institute for Genomic Research (TIGR) database: www.tigr.org University of Wisconsin, School of Veterinary Medicine Animal Health and Biomedical Sciendes (ASAP) website: asap.ahabs.wisc.edu

National Center for Biotechnology Information website: www.ncbi.nlm.nih.gov 